\title{
Validating a numerical phase change model by using infrared thermography
}

\author{
by R. Lehtiniemi ${ }^{1}$, P. Lamberg ${ }^{2}$, A.M. Henell ${ }^{1}$ \\ (1) Nokia Research Center, P.O. Box 407, FIN-00045 NOKIA GROUP, Finland. \\ e-mail: reijo.lehtiniemi@nokia.com \\ (2) Helsinki University of Technology, Laboratory of Heating, Ventilating and \\ Air-Conditioning, P.O. BOX 4400, FIN-02015 HUT, Finland.
}

\begin{abstract}
In this study, both the feasibility and accuracy of numerical methods in FEMLAB environment to simulate phase change events in a heat storage were studied. Two different storages were built and modelled, and the predictions were compared to experimental data. The results of the measurements followed the predictions rather well. According to the results, the applied models measurements allow a quick and flexible way to design phase change heat storages.
\end{abstract}

\section{Introduction}

Heat storages on the base of phase change material (PCM) are used to balance temporary temperature alternations in several practical application areas, ranging from portable and larger scale electronics [1-4] to automotive industry and buildings. When a temperature peak occurs, PCM absorbs the excessive energy by going through a phase transition and releases the absorbed energy slowly later after the peak. Thus, the use of PCM may offer a remarkable margin in time-dependent thermal management, providing that the thermal behaviour of the system is known.

The heat transfer in a PCM storage is a transient, non-linear phenomenon with a moving solid-liquid interface, generally referred to as "moving boundary" problem. Nonlinearity is the source of difficulties in moving boundary problems [5] and therefore only a few, limited analytical solutions of the phase change problems are known. In real PCM storage, numerical methods have to be used to achieve a sufficiently accurate solution for the heat transfer in the storage. There exists a wide range of different kinds of numerical methods to solve PCM problems, of which the most commonly used are the enthalpy method and the effective heat capacity method.

The aim of this study was to find out the accuracy and the feasibility of these most common algorithms in a straightforward FEMLAB environment for numerical solving of phase change problems in order to provide a fast and reliable way to define the optimal PCM container for widely varying telecommunication electronics applications.

To provide a well-controlled environment for the evaluation of simulation results, two specific PCM storages were manufactured: one with internal fins to enhance heat transfer from the walls to the PCM (Fig. 1a) and one simpler container otherwise similar but without the fins. Heat transfer in these storages, filled with paraffin as the PCM, was studied with both numerical methods. Experimental reference data for the validation was recorded by using thermocouples mounted inside the storage. Also the feasibility of an IR camera to perform fast, quantitative visualization of the case under study was tested.

\section{Theory and simulations}

Consider the heat storage shown in Fig. 1a. In a melting process, heat transfers from the heated walls to the phase change material first by conduction and later by natural convection that accelerates the melting. In both storages, the main heat transfer mode in the solidification process is conduction. The natural convection exists in the liquid-solid 
interface due the temperature difference in the liquid PCM, but even very strong natural convection in the solid-liquid interface has a negligible effect on the solid-liquid interface position compared to the effect of heat conduction in solid PCM [6].

\subsection{Enthalpy method}

In real phase change situations, there may occur more than one phase change interface or the interfaces can disappear totally. Furthermore, the phase change usually happens in a non-isothermal temperature range such as in the paraffin case. Then, tracking the solid-liquid interface may be difficult or even impossible.

From the calculation point of view, it is advantageous that the problem is reformulating in such a way that the moving boundary is implicitly bound up in a new form of equations that are applied in whole fixed domain. This can be done by introducing the so called enthalpy function, $H(T)$, which determines the sum of the sensible heat and the latent heat required for phase change [7]. The enthalpy form for the heat equation in two dimensions with initial and boundary conditions is

$$
\begin{aligned}
& \frac{\partial \mathrm{H}}{\partial \mathrm{t}}=\frac{\mathrm{k}_{\mathrm{I}}}{\rho}\left(\frac{\partial^{2} \mathrm{~T}}{\partial \mathrm{x}^{2}}+\frac{\partial^{2} \mathrm{~T}}{\partial \mathrm{y}^{2}}\right)+\mathrm{h}_{\mathrm{c}}\left(\frac{\partial \mathrm{T}}{\partial \mathrm{x}}+\frac{\partial \mathrm{T}}{\partial \mathrm{y}}\right) \\
& T(x, y, 0)=T_{i} \\
& T(0, y, t)=T(l, y, t)=T_{w}(t) \\
& \frac{\partial \mathrm{T}(\mathrm{x}, 0, \mathrm{t})}{\partial \mathrm{t}}=\frac{\mathrm{T}(\mathrm{x}, \mathrm{D}, \mathrm{t})}{\partial \mathrm{t}}=0
\end{aligned}
$$

where $\rho_{l}$ is the density, $c_{l}$ the heat capacity, $k_{l}$ the heat conductivity, $T_{l}$ the temperature, $l$ the length of the storage in $x$-direction, $h_{c}$ the convection heat transfer coefficient in liquid $\mathrm{PCM}$, and $D$ the height of the storage. In this study it is assumed that the convection heat transfer coefficient is zero during the solidification process.

Lamberg et al. [8] have presented the equation for the convection heat transfer coefficient in a rectangular storage containing paraffin according to studies of Marshall [9] and Eftekhar et al. [10]. The convection heat transfer coefficient during the melting process is

$$
h_{c}=0,072\left[\frac{\left[g\left(\frac{T_{w}-T_{m}}{2}\right) \rho_{1}^{2} c_{p \mid} k_{1}^{2} \beta\right]}{\mu}\right]^{1 / 3}
$$

where $\beta$ is the expansion coefficient, $\mu$ is the dynamic viscosity, and $g$ is the acceleration of gravity. The great advantage of the enthalpy method is that it can be used in any arbitrary materials, also other than phase change materials. For the phase change material $H(T)$ can be determined by DSC measurements.

\subsection{Effective heat capacity method}

With effective heat capacity, it is also possible to describe non-isothermal phase change in the PCM. The effective heat capacity of the material $\left(c_{\text {eff }}\right)$ is directly proportional to stored and released energy during the phase change and specific heat capacity but inversely proportional to the width of the melting or solidification temperature range:

$$
c_{\text {eff }}=\frac{L}{\left(T_{2}-T_{1}\right)}+c_{p}
$$


where $L$ is the latent heat of fusion, $T_{1}$ is the temperature where melting or solidification begins and $T_{2}$ is the temperature where the material is totally melted or solidified. The heat equation (Eq.1) with initial and boundary conditions is then

$$
\begin{aligned}
& \mathrm{C}_{\mathrm{p}} \frac{\partial \mathrm{T}}{\partial \mathrm{t}}=\frac{\mathrm{k}}{\rho}\left(\frac{\partial^{2} \mathrm{~T}}{\partial \mathrm{x}^{2}}+\frac{\partial^{2} \mathrm{~T}}{\partial \mathrm{y}^{2}}\right)+\frac{\mathrm{h}_{\mathrm{c}}}{\rho}\left(\frac{\partial \mathrm{T}}{\partial \mathrm{x}}+\frac{\partial \mathrm{T}}{\partial \mathrm{y}}\right) \\
& T(\mathrm{x}, \mathrm{y}, 0)=\mathrm{T}_{\mathrm{i}} \\
& T(0, \mathrm{y}, \mathrm{t})=\mathrm{T}(\mathrm{l}, \mathrm{y}, \mathrm{t})=\mathrm{T}_{\mathrm{w}}(\mathrm{t}) \\
& \frac{\partial \mathrm{T}(\mathrm{x}, 0, \mathrm{t})}{\partial \mathrm{t}}=\frac{T(\mathrm{x}, \mathrm{D}, \mathrm{t})}{\partial \mathrm{t}}=0
\end{aligned}
$$

where

$$
\mathrm{C}_{\mathrm{p}}=\left\{\begin{array}{l}
\mathrm{c}_{\mathrm{ps}}, \quad \mathrm{T}<\mathrm{T}_{1} \\
\frac{\mathrm{L}}{\left(\mathrm{T}_{2}-\mathrm{T}_{1}\right)}+\mathrm{C}_{\mathrm{p}} \quad, \mathrm{T}_{1} \leq \mathrm{T} \leq \mathrm{T}_{2} \\
\mathrm{C}_{\mathrm{pl}}, \quad \mathrm{T}>\mathrm{T}_{2}
\end{array}\right.
$$

The specific heat capacity of paraffin is defined separately for melting and freezing processes according to DSC measurements. In this paper, the temperature distribution of the storage is calculated with two different widths of the melting and solidification temperature range, $2^{\circ} \mathrm{C}$ and $7^{\circ} \mathrm{C} / 5^{\circ} \mathrm{C}$ (melting/freezing).

\section{Experimental set-up}

The heat storages for the measurements were made of solid Aluminium (AISi1MgT6, $k=174 \mathrm{~W} / \mathrm{mK}$ ) blocks by machining the interior off with electro-discharge method to ensure flawless heat transfer in Aluminium without any additional contact resistances due to joints.

The storages were equipped with Watlow Gordon K-type thermocouples of 40 AWG (approx. $0.08 \mathrm{~mm}$ ) diameter that were arranged as shown in Fig. 1a. The measurement points were set at about $2 \mathrm{~mm}$ intervals in the direction of heat transfer on special comblike supports which were fabricated of $300 \mu \mathrm{m}$ thick FR4 epoxy-glassfiber composite whose heat conductivity is as small as $0.3 \mathrm{~W} / \mathrm{mK}$. Due to their thinness and low conductivity, the effect of the supports on the PCM behaviour was neglected. The as thin as convenient thermocouple wires were guided out of the storage in the direction of isotherms to minimize their disturbance to the system.

The bottom of the container was sealed with chemically inert nitrile rubber mounted between the container and the bottom block to prevent leakage. The bottom block was made of Tufnol phenolic fabric with low through-plane thermal conductivity of $0.37 \mathrm{~W} / \mathrm{mK}$.

After the mounting and filling the storages to halfway with technical grade paraffin, the positions of the thermocouple sensors were determined optically with $0.01 \mathrm{~mm}$ accuracy and the filling was continued. Due to the volume expansion of about $5 \%$, corresponding container space at the top of the container was left empty after PCM solidification.

For the IR measurements, the emissivity of paraffin was determined experimentally by calibrating the IR camera against known temperatures both in solid and in liquid phase paraffin. A ZnSe infrared window with $70 \%$ transmission at the IR camera operating wavelength range was mounted as the lid of the PCM storage by using nitrile rubber sealing and phenolic fabric window support. The measurement set-up is shown in Fig. 1b. 
The two identical Aavid 6063-T5 Aluminium cold plates with an optimal coolant current of $4 \mathrm{l} / \mathrm{min}$ were mounted on opposite sides of the container to provide symmetry in the direction of heat transfer. The cold plates and the remaining walls of the storage were isolated from the room temperature environment with Styrofoam. The coolant liquid was water, the temperature and circulation of which was controlled by a Lauda RM6 liquid circulation chiller, which produces a preset temperature liquid flow (nominally $0.15 \mathrm{l} / \mathrm{s}$ ) and keeps the liquid temperature constant with $0.1^{\circ} \mathrm{C}$ accuracy by thermostatically controlled own cooler and heater, or alternatively, measures the temperature of the liquid used in circulation.

Finally, a FLIR SC3000 Quantum Well IR Photodetector (QWIP) camera was mounted so that it had a direct view to the PCM surface inside the storage behind the ZnSe IR window. The camera operates at 8-9 $\mu \mathrm{m}$ wavelength and is equipped with three lenses: standard optics $\left(20^{\circ} \times 15^{\circ}, 1.1 \mathrm{mrad}\right.$ IFOV), one close-up lens with $34 \mathrm{~mm} \times 26 \mathrm{~mm}$ and one with $10 \mathrm{~mm} \times 7.5 \mathrm{~mm}$ imaging areas. The thermal sensitivity of the camera at room temperature is $<20 \mathrm{mK}$ and its measurement accuracy better than $\pm 1 \%$ or $\pm 1^{\circ} \mathrm{C}$, whichever is larger. With the camera, it is possible to record $320 \times 240$ pixel live thermal image at $50 \mathrm{~Hz}$ frame rate.

\section{Measurements and results}

In the measurements, the liquid circulation chiller was first set to cool the cold plates to $+10^{\circ} \mathrm{C}$. After reaching the steady state, the cooling water temperature was set to $+40^{\circ} \mathrm{C}$ and the system was allowed to develop towards the new equilibrium. The up ramp stage for the cold plates typically took about $15 \mathrm{~min}$. After all the PCM had melted and the system was in the $+40^{\circ} \mathrm{C}$ steady state, the cooling water temperature was set back to $+10^{\circ} \mathrm{C}$. The cooling phase of the cycle lasted typically about $80 \mathrm{~min}$.

The entire $10^{\circ} \mathrm{C}-40^{\circ} \mathrm{C}-10^{\circ} \mathrm{C}$ cycle took about $2.5-3$ hours and it was repeated at least five times for each measurement case. For each cycle, the temperature responses of either eight (storage with no fins) or 16 (finned storage) thermocouples and the thermal images of the PCM surface were recorded at one minute intervals. Typical results for the example point in the middle of the finned storage (shown also in Fig. 1a, distance $A$ $(8.57 \pm 0.01) \mathrm{mm}$ from the top heated wall, distance $B(8.40 \pm 0.01) \mathrm{mm}$ from the left fin) are presented in Fig. 2a, where thermocouple results and numerical predictions (enthalpy, effective heat capacity with both phase change ranges) are visible. Fig. $2 b$ depicts the experimental deviation between the thermocouple and IR measurements, and Figs. 3a and $b$ show 2-D false colour representations of the temperature at a certain time step given by FEM and IR camera.

As can be seen, the graphs correspond to each other rather well. The about one degree deviation in the higher IR temperatures is due to an internal calibration error in the camera, which was experimentally verified. When all numerical and experimental results are compared to each other, every numerical method gives a good estimation of melting and freezing processes. The small deviation is that numerically the PCM tends to heat up and to cool down slightly too fast in the solid state. In the solidification process when the PCM is in the liquid state, the numerical results for the temperature of the PCM follow well the experimental results. The effective heat capacity method with the narrow temperature range gives the most precise result for the temperature of the PCM compared to experimental results.

\section{Conclusions}

According to the results, both algorithms seem to work reasonably well in FEMLAB software environment. The easiness of varying geometries and parameters enables faster design of tailored PCM storages for various electronics applications. The essential result is that time, effort, and cost can be saved. 
Between the numerical predictions and measurements, the largest error occurs with solid material. One reason for the difference are the material properties of the PCM, which were assumed constant. If the temperature dependence of material properties were known, numerical methods would give more precise results. Other reason for the differences may be that the locations of the thermocouples may have slightly moved when the storages were filled with liquid PCM. Although thermocouples in this study provided more reliable results, the feasibility of infrared thermography and its capability for quantitative visualization by using infrared windows was confirmed.

In the following research phase, advanced structures like honeycombs and PCM-filled foams as well as local, separate heat sources emulating components on printed wiring board will be studied.

\section{Acknowledgements}

The authors would like to thank Mr. C.-M. Fager for performing the measurements, Mr. J. Manner, Mr. K. Kuittinen and Mr. M. Roos for valuable support in preparing the containers, as well as Dr. J. Rantala for providing the working conditions at Nokia Research Center.

\section{REFERENCES}

[1] ALAWADHI, E.M. AND AMON, C.H., "PCM thermal storage unit for time-dependent thermal management of electronic devices", ASME $34^{\text {th }}$ National Heat Transfer Conference, 2000.

[2] HODES, M., MANZIONE, L., CHEN, C., WEINSTEIN, R.D., PENCE, S.J., AND TALIER, J.A., "Transient thermal management of handsets using phase change materials", ASME 34 $4^{\text {th }}$ National Heat Transfer Conference, 2000.

[3] LIU, B. AND MAJUMDAR, P. "Numerical simulation of phase change heat transfer in PCM-encapsulated heat sinks", Eighteenth Annual IEEE Symposium on Semiconductor Thermal Measurement and Management, pp. 88-91, 2002.

[4] YOO, D. AND JOSHI, Y., "Energy efficient thermal management of electronic components using solid liquid phase change materials", The Eighth Intersociety Conference on Thermal and Thermomechanical Phenomena in Electronic Systems ITHERM, pp. 800-807, 2002.

[5] ALEXIADES, V. AND SOLOMON, A. D., Mathematical modelling of melting and freezing processes. Hemisphere Publishing Corporation, USA, 1993.

[6] KROEGER, P.G. AND OSTRACH, S., "The solution of a two-dimensional freezing problem including convection effects in the liquid region", Int. J. Heat Mass Transfer, Vol. 17, pp. 1191-1207, 1973.

[7] CRANK, J., "Free and moving boundary problems", Oxford University Press, 1984.

[8] LAMBERG, P. AND SIRÉN, K., "Analytical model for melting in a semi-infinite PCM storage with an internal fin", Int. J. Heat Mass Transfer, published in electronic format, 2002.

[9] MARSHALL, R. "Experimental determination of heat transfer coefficient in a thermal storage containing a phase change material - The rectangular cavity", International conference on future energy concept, pp.216-220, 1979.

[10] EFTEKHAR, J., HAJI-SHEIKH, A. AND LOU, D., "Heat transfer enhancement in a paraffin wax thermal energy storage system", Journal of Solar Energy Engineering, Vol. 106, pp. 299-306, 1984. 

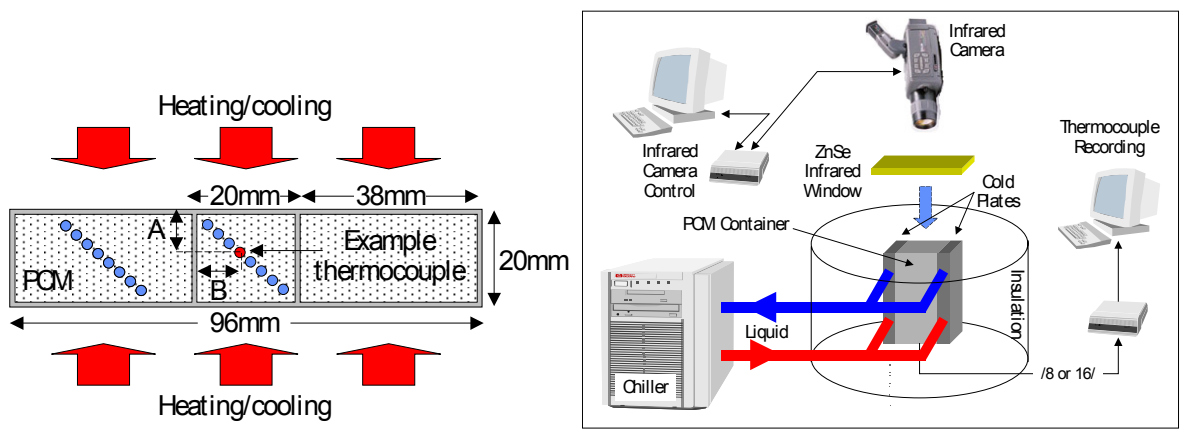

Fig. 1. A schematic drawing of a) an Aluminium PCM heat storage (the other storage is similar but without the heat transfer fins), and b) of the experimental setup.
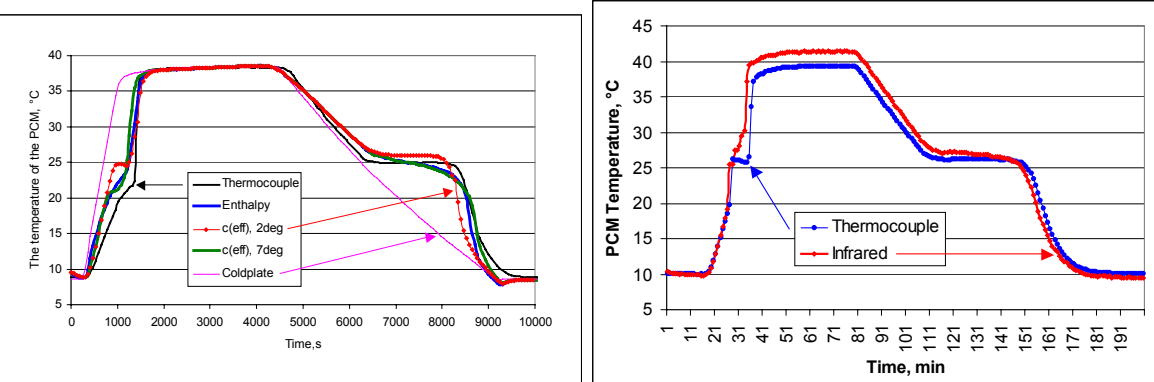

Fig. 2. a) Temperature behaviour of the example point during the cycle from $10^{\circ} \mathrm{C}$ to $40{ }^{\circ} \mathrm{C}$. The graph shows both numerical and experimental results. b) Deviation between thermocouple and infrared measurements.
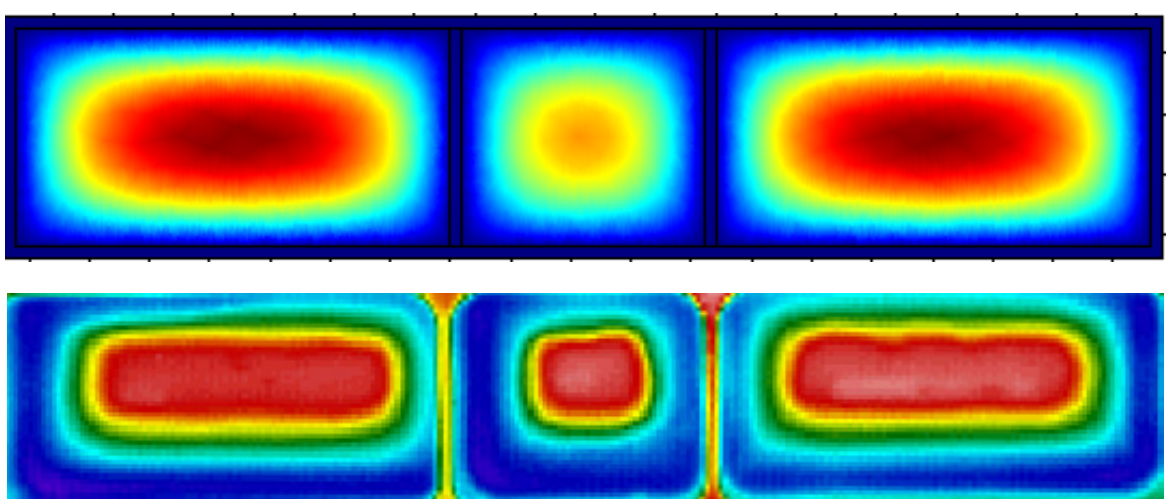

Fig. 3. 2-D Temperature distribution in the PCM storage: a) FEM model, b) thermographic image. The IR image is asymmetric due to camera tilting to avoid reflections from the $\mathrm{ZnSe}$ window surface. 